\title{
The fatty acid compositions of erythrocyte and plasma polar lipids in children with autism, developmental delay or typically developing controls and the effect of fish oil intake
}

\author{
John Gordon Bell ${ }^{1}$, Deborah Miller ${ }^{2}$, Donald J. MacDonald ${ }^{3}$, Elizabeth E. MacKinlay ${ }^{1}$, James R. Dick ${ }^{1}$, \\ Sally Cheseldine ${ }^{4}$, Rose M. Boyle ${ }^{3}$, Catriona Graham ${ }^{5}$ and Anne E. O'Hare ${ }^{2}$ \\ ${ }^{1}$ Nutrition Group, Institute of Aquaculture, University of Stirling, Stirling FK9 4LA, UK \\ ${ }^{2}$ Department of Child Life and Health, University of Edinburgh, 20 Sylvan Place, Edinburgh EH9 1UW, UK \\ ${ }^{3}$ Biochemistry Department, Victoria Infirmary, Langside Road, Glasgow G42 9TY, UK \\ ${ }^{4}$ CFMHS, 3 Rillbank Terrace, Edinburgh EH9 1LL, UK \\ ${ }^{5}$ Epidemiology and Statistics Core, Wellcome Trust Clinical Research Facility, Western General Hospital, Edinburgh \\ EH4 $2 X U, U K$ \\ (Received 21 May 2009 - Revised 7 October 2009 - Accepted 14 October 2009 - First published online 9 December 2009)
}

\begin{abstract}
The erythrocyte and plasma fatty acid compositions of children with autism were compared in a case-control study with typically developing (TD) children and with children showing developmental delay (DD). Forty-five autism subjects were age-matched with TD controls and thirty-eight with DD controls. Fatty acid data were compared using paired $t$ tests. In addition, blood fatty acids from treatment-naive autism subjects were compared with autism subjects who had consumed fish oil supplements by two-sample $t$ tests. Relatively few differences were seen between erythrocyte fatty acids in autism and TD subjects although the former had an increased arachidonic acid (ARA):EPA ratio. This ratio was also increased in plasma samples from the same children. No changes in $n$-3 fatty acids or ARA:EPA ratio were seen when comparing autism with DD subjects but some SFA and MUFA were decreased in the DD subjects, most notably 24:0 and 24:1, which are essential components of axonal myelin sheaths. However, if multiple comparisons are taken into account, and a stricter level of significance applied, most of these values would not be significant. Autism subjects consuming fish oil showed reduced erythrocyte ARA, 22:4n-6, 22:5n-6 and total n-6 fatty acids and increased EPA, 22:5n-3, $22: 6 n-3$ and total $n-3$ fatty acids along with reduced $n-6: n-3$ and ARA:EPA ratios. Collectively, the autism subjects did not have an underlying phospholipid disorder, based on erythrocyte fatty acid compositions, although the increased ARA:EPA ratio observed suggested that an imbalance of essential highly unsaturated fatty acids may be present in a cohort of autism subjects.
\end{abstract}

Blood fatty acids: Autism: Child health: $n-3$ Highly unsaturated fatty acids: Fish oils

Autism is a behaviourally defined condition, with no definitive biomarkers, characterised by impairments in social interactions, verbal and non-verbal communications, and by restricted and repetitive stereotypical behaviours. Autism spectrum disorders are considered to be aetiologically and phenotypically heterogeneous. Until the mid-late $1980 \mathrm{~s}$ autism was a relatively rare condition with a prevalence of 5-10 per 10000 of the population. However, over the last 15 years autism rates have increased such that it is now the most prevalent serious childhood developmental disorder in the developed world with a rate in the $\mathrm{UK}$ of 1 in $100^{(1,2)}$. However, there is considerable debate regarding the reasons for and the extent of the increase, with some authors claiming that changes are due largely to widened diagnostic criteria while others claim that the increased prevalence is a reality and perhaps underestimated ${ }^{(3,4)}$.
Over the past 10 years, a number of behavioural and learning disorders have been associated with suboptimal cellular fatty acid status including attention deficit hyperactivity disorder (ADHD), dyslexia, dyspraxia and autism ${ }^{(5)}$. Similarly, a number of neurological and neurodegenerative disorders including schizophrenia, unipolar and bipolar depression and postnatal depression have been linked to reduced erythrocyte and plasma fatty acid concentrations that may be related to changes in lipid metabolism ${ }^{(6)}$.

The principal highly unsaturated fatty acids (HUFA) in neural tissues are DHA of the $n-3$ series $(22: 6 n-3)$ and arachidonic acid (20:4n-6; ARA) of the $n-6$ series. The brain is about $60 \%$ lipid, largely phospholipid (PL), and of this lipid the majority is made up of DHA and ARA that together represent more than $20 \%$ of the brain dry weight

Abbreviations: ADHD, attention deficit hyperactivity disorder; ARA, arachidonic acid; BHT, butylated hydroxytoluene; DD, developmental delay; DMA, dimethyl acetals; FAME, fatty acid methyl esters; HUFA, highly unsaturated fatty acids; LT, leukotrienes; PL, phospholipid; RHSC, Royal Hospital for Sick Children; TD, typically developing.

* Corresponding author: Professor Gordon Bell, fax +44 1786 472133, email g.j.bell@stir.ac.uk 
and more than $30 \%$ of retinal weight ${ }^{(7,8)}$. The essential HUFA, EPA $(20: 5 n-3)$ is not generally enriched in neural tissues but has significant anti-inflammatory activity due to its ability to compete with ARA, and attenuate the production of ARA-derived eicosanoids in tissues and cell membranes ${ }^{(8,9)}$. Classically, the essential fatty acids in humans are regarded as the $\mathrm{C} 18$ fatty acids linoleic (18:2n-6) and $\alpha$-linolenic $(18: 3 n-3)$ acids, although these require further metabolism by a series of desaturation and elongation reactions to form their functional HUFA, namely, ARA, EPA and $\mathrm{DHA}^{(10)}$. However, while these pathways exist in humans the conversion of $18: 3 n-3$ to DHA is very poor, with between 0.05 and $4 \%$ being converted, which suggests that requirements for HUFA will not be met without significant exogenous supply ${ }^{(11)}$. Interestingly, this conversion is higher in women than men, particularly during pregnancy when conversion efficiency can increase to $9 \%^{(12,13)}$. This fact may be relevant to the sex ratio seen in autism where the ratio of prevalence is more than $4: 1$ in favour of males ${ }^{(14)}$.

As described above, the fatty acid composition of the brain and neural tissues is unique with respect to their high HUFA concentrations. Recently, many functions for these HUFA have been elucidated including regulation of signal transduction ${ }^{(15)}$, neuro-inflammation ${ }^{(16)}$ and cellular repair and survival ${ }^{(17)}$. The cell membrane PL are enriched in HUFA, especially in the $s n-2$ position, and these membranes are subject to constant breakdown and re-synthesis to maintain membrane integrity. The replacement HUFA for PL synthesis are obtained from the circulating plasma and may be directly from dietary sources or from the actions of synthetic pathways in vivo. Recent studies have found polymorphisms in the gene cluster associated with the fatty acid desaturase-2 gene (FADS2) for $\Delta 6$-desaturase in patients with $\mathrm{ADHD}^{(18,19)}$. As $\Delta 6$-desaturase is the ratelimiting step in HUFA synthesis, reduced expression could reduce HUFA availability and a reduction in cellular concentrations.

A number of papers have reported changes in erythrocyte and plasma fatty acids in autism patients. Vancassel et al. ${ }^{(20)}$ observed significantly reduced $n-3$ PUFA and an increased $n-6: n-3$ ratio in plasma PL from autism patients compared with those who they designated as intellectually impaired patients. Similar changes were seen in erythrocyte PL from children with classical or early-onset and regressive autism compared with adult controls, although in addition there were decreased levels of total dimethyl acetals (DMA) and increased ARA:EPA ratios, $24: 1$ and $22: 5 n-6$ in the autism patients compared with controls ${ }^{(21)}$. Stearic acid $(18: 0)$, total SFA and $18: 2 n-6$ were significantly increased and $18: 1 n-9$, total MUFA and ARA were significantly reduced in regressive autism patients compared with controls ${ }^{(21)}$. In addition, erythrocyte type IVA phospholipidase $\mathrm{A}_{2}$ concentrations were significantly higher in both autism groups compared with adult controls. In a recent study in California, erythrocyte PL fatty acid compositions were measured in twenty age-matched patients with regressive autism, early-onset autism, twenty patients with non-autistic developmental disabilities and twenty typically developing (TD) controls ${ }^{(22)}$. Their main findings were increased levels of $20: 1 n-9$ and $22: 1 n-9$ in regressive autism subjects compared with TD controls. In addition, 20:2n-6 was increased and trans-16:1n-7 was decreased in patients with regressive autism compared with early-onset autism patients $^{(22)}$.

In the present study, it was planned to collect blood samples from three groups of children, who had respectively a diagnosis of autism or were developmentally delayed (DD) or were considered TD. Erythrocyte and plasma PL fatty acid compositions were measured in all three groups as well as in a smaller number of patients with autism who had consumed fish oils in the 6 months before sampling. The primary hypothesis tested in the present study was that children with autism have a lipid metabolic disorder that can be characterised by changes in circulating fatty acids, and in particular, but not exclusively, by reduced concentrations of essential HUFA (ARA, EPA and DHA) in erythrocyte and plasma PL. In the autism group receiving fish oil we hoped to establish whether such supplementation would result in increased membrane levels of the $n-3$ HUFA and reduced n-6 HUFA.

\section{Materials and methods}

\section{Study participants}

A total of 330 children were approached as part of the present case-control study. Of these, 198 had a diagnosis of autism, forty-five had DD and eighty-seven were classed as TD. Of these, forty-nine were recruited for inclusion in the study from the autism group, thirty-nine in the DD group and fifty-two in the TD group. Reasons for rejection included: taking fish oil supplements (thirty-five, two and fourteen subjects in the autism, DD and TD groups, respectively); taking steroids (five, one and seven subjects, respectively); and other reasons (fourteen, three and five subjects, respectively). The autism study participants were either existing patients of the Royal Hospital for Sick Children (RHSC), Edinburgh or were recruited from the Lothian National Health Service (NHS) catchment area. The subjects with autism met the criteria for autistic disorders by the Autism Diagnostic Interview - Revised (ADI-R) ${ }^{(23)}$, which is a comprehensive investigative-based interview that covers most developmental and behavioural aspects of autism. The ADI-R has a diagnostic algorithm that maps to both Diagnostic and Statistical Manual for Mental Disorders, 4th ed. (DSM-IV) and International Classification of Diseases 10th Revision (ICD-10) criteria for the diagnosis of autistic disorder. In addition, the diagnosis of autism had been made by either a Consultant Paediatrician or Child and Adolescent Psychiatrist according to evidence-based guidelines ${ }^{(24)}$ which included multidisciplinary specialist assessment, the employment of a classification system ${ }^{(25,26)}$ and the use of a published diagnostic instrument ${ }^{(27)}$.

The first control group was of TD children who were matched on chronological age and who were visiting outpatient clinics for investigative procedures or undergoing elective surgery. They donated part of the blood sample being drawn for routine investigations. These controls measured within the normal ranges on the Strengths and Difficulties Questionnaire ${ }^{(28)}$. The second control group comprised children with learning disabilities and/or 
generalised DD who were matched to the children with autistic disorder on the Vineland Adaptive Behaviour Scales ${ }^{(29)}$. Not all cases or controls were able to be matched. However, thirty-eight pairs of autism cases were age- and sex-matched with DD controls where the age matching in this case was done using developmental age as assessed by Vineland and forty-five pairs of autism cases were age- and sex-matched to TD controls using chronological age. In addition to the original research aims, and due to the high number of children with autism who were taking fish oil supplements, it was decided to analyse samples from twenty-one subjects with autism who had taken fish oil and compare them with the forty-nine autism subjects described above. The present study was conducted according to the guidelines laid down in the Declaration of Helsinki and all procedures involving human patients were approved by the Lothian Research Ethics Committee (LREC reference 04/S1103/51). Written consent was obtained from all parents. The sampled population included forty-nine children with autism, aged 7.5 (SD 3.5) years (89.6 months), including five females, thirty-nine children with DD, aged 6.0 (SD 3.3) years (72.2 months), including four females and fifty-two TD children, aged 7.5 (SD 3.6) years (89.9 months), including three females.

\section{Blood collection}

Whole blood $(4 \mathrm{ml})$ was collected by phlebotomists at the RHSC Edinburgh, into tubes containing EDTA as anticoagulant (Teklab Medical Laboratories, Durham, UK). The blood was centrifuged $(1000 \mathrm{~g} ; 5 \mathrm{~min}$.$) and the plasma$ removed and retained. In addition, the buffy coat and the top $2 \mathrm{~mm}$ of erythrocytes were removed using a Pasteur pipette and placed in a separate vial. The remaining packed erythrocytes were split into two samples and stored at $-70^{\circ} \mathrm{C}$ at the biochemistry laboratories at the RHSC. Samples were frozen at $-70^{\circ} \mathrm{C}$ in a freezer within $60 \mathrm{~min}$ of collecting the blood sample. Each sample was assigned a numbered code that was known only to project staff at the RHSC so that samples were analysed blind by staff at Stirling for polar lipid fatty acid compositions of erythrocyte and plasma. Samples were collected from the RHSC every 2 months and delivered to Stirling on dry ice where they were stored at $-70^{\circ} \mathrm{C}$ until analysed.

Lipid extraction, preparation of phospholipid fraction and preparation of fatty acid methyl esters in erythrocytes and plasma

The lipid extraction was a modification of the method of Bligh \& Dyer ${ }^{(30)}$. The erythrocyte pellet was thawed and $0 \cdot 25-0.50 \mathrm{ml}$ placed in a $15 \mathrm{ml}$ stoppered tube. Then $5 \mathrm{ml}$ methanol-0.01\% butylated hydroxytoluene (BHT, w/v) was added and then mixed on a vortex mixer. After $20 \mathrm{~min}$ at room temperature $2.5 \mathrm{ml}$ chloroform-BHT was added, mixed and left at room temperature for a further $40 \mathrm{~min}$. The tubes were centrifuged at $500 \mathrm{~g}$ for $5 \mathrm{~min}$ and the supernatant fraction decanted into a clean $15 \mathrm{ml}$ tube after filtering though Whatman no. 1 paper. A further $2.5 \mathrm{ml}$ chloroform-BHT and $2.5 \mathrm{ml}$ of $0.88 \% \mathrm{KCl}(\mathrm{w} / \mathrm{v})$ were added, mixed and centrifuged as above. The lower chloroform layer was removed and filtered into a $15 \mathrm{ml}$ tube and evaporated under $\mathrm{N}_{2}$. The lipid was taken up in $0.8 \mathrm{ml}$ chloroform-methanol $(2: 1, \mathrm{v} / \mathrm{v})$ and placed in a weighed glass vial. This was dried under $\mathrm{N}_{2}$ and desiccated for $16 \mathrm{~h}$. After recording the lipid weight the sample was re-suspended in chloroform-methanol $(2: 1, \mathrm{v} / \mathrm{v})+\mathrm{BHT}$, at a concentration of $10 \mathrm{mg} / \mathrm{ml}$ and stored at $-70^{\circ} \mathrm{C}$ until analysed.

Plasma samples $(0.5 \mathrm{ml})$ were extracted by the method of Folch et al. ${ }^{(31)}$ in $10 \mathrm{ml}$ chloroform-methanol $(2: 1, \mathrm{v} / \mathrm{v})$, washed with $0.88 \% \mathrm{KCl} \mathrm{(w/v)} \mathrm{and} \mathrm{filtered} \mathrm{and} \mathrm{dried}$ as above. Final lipid extracts were re-suspended in chloroform-methanol $(2: 1, \mathrm{v} / \mathrm{v})+\mathrm{BHT}$, at a concentration of $10 \mathrm{mg} / \mathrm{ml}$ and stored at $-70^{\circ} \mathrm{C}$ until analysed.

A PL fraction was prepared from $0.5 \mathrm{mg}$ of total lipid applied to a $20 \times 20 \mathrm{~cm}$ silica gel 60 TLC plate (VWR, Lutterworth, Leics, UK) and developed in isohexane-diethyl ether-acetic acid (80:20:1, by vol.) and dried for a few minutes at room temperature. The plate was sprayed lightly with 2,7 , dichlorofluorescein $(0.1 \%$, $\mathrm{w} / \mathrm{v})$ in $97 \%$ methanol (v/v) and the PL bands on the origin scraped from the plate and placed in a $15 \mathrm{ml}$ testtube. Fatty acid methyl esters (FAME) were prepared by acid-catalysed transesterification in $2 \mathrm{ml}$ of $1 \% \mathrm{H}_{2} \mathrm{SO}_{4}$ in methanol at $50^{\circ} \mathrm{C}$ overnight ${ }^{(32)}$. The samples were neutralised with $2.5 \mathrm{ml}$ of $2 \% \mathrm{KHCO}_{3}$ and extracted with $5 \mathrm{ml}$ isohexane-diethyl ether $(1: 1, \mathrm{v} / \mathrm{v})+$ BHT. The samples were then re-extracted with $5 \mathrm{ml}$ isohexane-diethyl ether $(1: 1, \mathrm{v} / \mathrm{v})$ and the combined extracts dried and dissolved in $0.3 \mathrm{ml}$ isohexane before fatty acid analysis.

\section{Measurement of erythrocytes and plasma fatty acids}

FAME were separated and quantified by GLC (Fisons 8160; Carlo Erba, Milan, Italy) using a $60 \mathrm{~m} \times 0.32 \mathrm{~mm} \times 0.25 \mu \mathrm{m}$ film thickness capillary column (ZB-WAX; Phenomenex, Macclesfield, Cheshire, UK). $\mathrm{H}_{2}$ was used as the carrier gas at a flow rate of $4.0 \mathrm{ml} / \mathrm{min}$ and the temperature programme was from 50 to $150^{\circ} \mathrm{C}$ at $40^{\circ} \mathrm{C} / \mathrm{min}$ then to $195^{\circ} \mathrm{C}$ at $2^{\circ} \mathrm{C} / \mathrm{min}$ and finally to $215^{\circ} \mathrm{C}$ at $0.5^{\circ} \mathrm{C} / \mathrm{min}$. Individual FAME were identified compared with well-characterised inhouse standards as well as commercial FAME mixtures (Supelco $^{\text {тм }} 37$ FAME mix; Sigma-Aldrich Ltd, Gillingham, Dorset, UK).

\section{Statistical analysis}

To determine if there were any differences between fatty acid compositions in autism cases and age- and sex-matched TD controls, or DD controls, paired $t$ tests were used. To compare the fatty acid compositions of the autism group ( $n$ 49) with autism patients who were excluded from the main trial due to consumption of fish oils ( $n$ 21) a two-sample $t$ test was used. The level of significance was set initially at $P<0 \cdot 05$.

\section{Results}

In total, 330 children were identified from the Lothian National Health Service (NHS) trust catchment as being potential participants in the present study. Of these, 140 
children agreed or were suitable for participation. The reasons for non-suitability were varied and included consumption of fish oil supplements in the previous 6 months and taking steroids. The percentage of participants already consuming fish oils represented $18 \%$ of the autism group, $16 \%$ of the TD group and $4 \%$ of the DD group.

When comparing the erythrocyte polar lipid fatty acid data of the autism and TD groups (Table 1) only a few fatty acids or ratios were different $(P<0 \cdot 05)$. $\alpha$-Linolenic acid $(18: 3 n-3)$, the precursor for the longer-chain $n-3$ HUFA, was reduced in the autism group compared with the TD group while the ARA:EPA ratio was increased. The plasma polar lipid fatty acid compositions in the pair-matched autism and TD groups showed very few differences (Table 1). The minor SFA $14: 0$ and 15:0 were reduced while the $n-6: n-3$ and ARA:EPA ratios were increased in the autism group compared with the TD group.

When comparing the erythrocyte polar lipid fatty acid data between pair-matched children from the autism and DD groups (Table 2) the SFA 20:0, 22:0 and 24:0 as well as the MUFA $16: 1 n-9,20: 1 n-9,22: 1 n-9$ and $24: 1 n-9$ were all increased in the autism group compared with the DD group. In addition, the $18: 1 n-7$ DMA fatty acid was increased in the autism group compared with the DD group. By comparison, the total $n-6$ fatty acids and the total PUFA were reduced in the autism group compared with the DD group.

Relatively minor changes were also seen in the plasma polar lipid fatty acid compositions when comparing pair-matched autism and DD subjects (Table 2). The SFA 20:0 and total saturates were reduced in the autism compared with the DD group while 18:1n-9 DMA and total DMA were increased in the autism group compared with the DD group.

The erythrocyte polar lipid fatty acid compositions in autism patients compared, using two-sample $t$ tests, with autism patients who had consumed fish oil supplements showed a number of differences between treatment groups (Table 3). Of the twenty-one autism patients who had consumed fish oils, fifteen had taken Eye $\mathrm{Q}^{\mathrm{TM}}$ (Equazer, Wallingford, Oxfordshire, UK), one had taken Haliborange-3 (Seven Seas Ltd, Hull, UK) and one had taken Eskimo- $3^{\circledR}$ (Whaley Bridge, Derbyshire, UK) while four did not specify the fish oil product. Among the MUFA, 18:1n-7 was decreased in the autism compared with the autism + fish oil group. In the $n-6$ fatty acids, ARA, 22:4n-6 and $22: 5 n-6$ were reduced in the autism + fish oil group compared with the autism group. The reductions in $n-6$ HUFA were reversed in the n-3 HUFA which had increased EPA, 22:5n-3, DHA and total $n-3$ HUFA in the autism + fish oil group compared with the autism group. In addition, the $n-6: n-3$ ratio and the ARA:EPA ratio were both reduced in the autism + fish oil group compared with the autism group (Table 3 ).

The plasma polar lipid fatty acid compositions in autism patients compared, using two-sample $t$ tests, with autism patients who had consumed fish oil supplements showed a number of differences similar to those seen in the erythrocyte data described above (Table 3). The MUFA 18:1n-7 was increased, as seen in erythrocytes, but $18: 1 n-9$ and $20: 1 n-9$ were decreased and increased, respectively, in the autism + fish oil group. ARA was not different in plasma

Table 1. Fatty acid compositions of erythrocyte and plasma polar lipids (weight \% of total fatty acids) in autism and typically developing (TD) subject groups ( $n$ 45, pair-matched)

(Mean values and standard deviations)

\begin{tabular}{|c|c|c|c|c|c|c|c|c|c|c|}
\hline \multirow[b]{3}{*}{ Fatty acids } & \multicolumn{4}{|c|}{ Erythrocytes } & \multirow[b]{3}{*}{$P$} & \multicolumn{4}{|c|}{ Plasma } & \multirow[b]{3}{*}{$P$} \\
\hline & \multicolumn{2}{|c|}{ Autism } & \multicolumn{2}{|c|}{ TD } & & \multicolumn{2}{|c|}{ Autism } & \multicolumn{2}{|c|}{ TD } & \\
\hline & Mean & SD & Mean & SD & & Mean & SD & Mean & SD & \\
\hline \multicolumn{11}{|l|}{ Saturates } \\
\hline $14: 0$ & 0.32 & 0.13 & 0.36 & 0.11 & 0.093 & 0.34 & 0.14 & 0.44 & 0.13 & $0.001^{*}$ \\
\hline $15: 0$ & 0.19 & 0.06 & $0 \cdot 21$ & 0.05 & 0.227 & 0.20 & 0.07 & 0.25 & 0.07 & $0.004^{*}$ \\
\hline Total saturates & $39 \cdot 33$ & 1.69 & 39.55 & $1 \cdot 38$ & 0.527 & $42 \cdot 23$ & $1 \cdot 37$ & $42 \cdot 69$ & $1 \cdot 21$ & 0.102 \\
\hline \multicolumn{11}{|l|}{ Monoenes } \\
\hline $20: 1 n-9$ & 0.35 & 0.08 & 0.33 & 0.07 & 0.398 & $0 \cdot 20$ & 0.07 & 0.23 & $0 \cdot 10$ & 0.068 \\
\hline $24: 1 n-9$ & $2 \cdot 15$ & 0.41 & $2 \cdot 00$ & 0.29 & 0.082 & 0.95 & 0.26 & 1.02 & 0.26 & 0.141 \\
\hline Total monoenes & $17 \cdot 27$ & 1.59 & $16 \cdot 86$ & 1.04 & 0.161 & $14 \cdot 84$ & $2 \cdot 33$ & $14 \cdot 63$ & 1.82 & 0.632 \\
\hline \multicolumn{11}{|l|}{$n-6$} \\
\hline $18: 2 n-6$ & 11.58 & 1.44 & 11.49 & 1.47 & 0.793 & 21.45 & $3 \cdot 24$ & 21.01 & 2.72 & 0.490 \\
\hline $20: 4 n-6$ & 13.52 & $1 \cdot 15$ & 13.51 & $1 \cdot 15$ & 0.953 & $10 \cdot 15$ & 1.67 & 9.96 & 1.44 & 0.605 \\
\hline $22: 4 n-6$ & $2 \cdot 61$ & 0.43 & 2.52 & 0.43 & 0.369 & 0.48 & 0.10 & 0.45 & 0.10 & $0 \cdot 213$ \\
\hline $22: 5 n-6$ & 0.55 & 0.13 & 0.53 & 0.13 & 0.411 & 0.27 & 0.10 & 0.25 & 0.08 & $0 \cdot 204$ \\
\hline Total $n-6$ & $30 \cdot 76$ & 1.69 & 30.51 & 1.41 & 0.501 & $36 \cdot 13$ & $2 \cdot 61$ & 35.5 & 2.39 & 0.211 \\
\hline \multicolumn{11}{|l|}{$n-3$} \\
\hline $18: 3 n-3$ & 0.15 & 0.06 & 0.20 & 0.13 & $0.042^{*}$ & 0.19 & 0.10 & 0.23 & 0.10 & 0.051 \\
\hline $20: 5 n-3$ & 0.53 & 0.24 & 0.58 & 0.20 & 0.317 & 0.60 & 0.29 & 0.69 & 0.32 & 0.184 \\
\hline $22: 5 n-3$ & 2.01 & 0.44 & $2 \cdot 10$ & 0.27 & 0.251 & 0.94 & 0.22 & 0.96 & 0.15 & 0.553 \\
\hline $22: 6 n-3$ & $3 \cdot 30$ & 1.04 & $3 \cdot 61$ & 0.93 & 0.138 & $2 \cdot 58$ & 0.78 & $2 \cdot 81$ & 0.72 & 0.153 \\
\hline Total $n-3$ & 6.04 & $1 \cdot 34$ & 6.53 & $1 \cdot 24$ & 0.077 & $4 \cdot 39$ & 1.06 & $4 \cdot 80$ & 1.03 & 0.079 \\
\hline Total PUFA & 36.79 & $1 \cdot 76$ & 37.04 & 1.63 & 0.499 & 40.52 & 2.43 & 40.29 & $2 \cdot 13$ & 0.618 \\
\hline$n-6: n-3$ & $5 \cdot 39$ & 1.42 & $4 \cdot 86$ & 1.04 & 0.054 & 8.79 & 2.56 & $7 \cdot 75$ & 1.82 & $0.035^{\star}$ \\
\hline $20: 4 n-6: 20: 5 n-3$ & 31.69 & $17 \cdot 40$ & 25.98 & $8 \cdot 21$ & $0.047^{\star}$ & 22.95 & $15 \cdot 88$ & $16 \cdot 96$ & 6.69 & $0.021^{*}$ \\
\hline
\end{tabular}

${ }^{*} P<0.05$ 
Table 2. Fatty acid compositions of erythrocyte and plasma polar lipids (weight $\%$ of total fatty acids) in autism and developmental delay (DD) subject groups ( $n 38$, pair-matched)

(Mean values and standard deviations)

\begin{tabular}{|c|c|c|c|c|c|c|c|c|c|c|}
\hline \multirow[b]{3}{*}{ Fatty acids } & \multicolumn{4}{|c|}{ Erythrocytes } & \multirow[b]{3}{*}{$P$} & \multicolumn{4}{|c|}{ Plasma } & \multirow[b]{3}{*}{$P$} \\
\hline & \multicolumn{2}{|c|}{ Autism } & \multicolumn{2}{|c|}{ DD } & & \multicolumn{2}{|c|}{ Autism } & \multicolumn{2}{|c|}{$\mathrm{DD}$} & \\
\hline & Mean & SD & Mean & SD & & Mean & SD & Mean & SD & \\
\hline \multicolumn{11}{|l|}{ Saturates } \\
\hline $20: 0$ & 0.27 & 0.04 & 0.24 & 0.04 & $0.020^{*}$ & 0.28 & 0.08 & 0.32 & 0.06 & $0.022^{*}$ \\
\hline $22: 0$ & 0.89 & 0.14 & 0.77 & 0.11 & $0.002^{*}$ & 0.65 & $0 \cdot 19$ & 0.73 & 0.18 & 0.066 \\
\hline $24: 0$ & 1.99 & 0.31 & 1.79 & 0.25 & $0.004^{*}$ & 0.54 & 0.17 & 0.59 & 0.16 & 0.135 \\
\hline Total saturates & $39 \cdot 15$ & 1.54 & 38.72 & 1.29 & 0.230 & $42 \cdot 32$ & 1.32 & $42 \cdot 90$ & 1.02 & 0.047 \\
\hline \multicolumn{11}{|l|}{ Monoenes } \\
\hline $16: 1 n-9$ & 0.14 & 0.06 & $0 \cdot 19$ & 0.08 & $0.007^{*}$ & 0.25 & 0.09 & 0.24 & 0.07 & 0.333 \\
\hline $20: 1 n-9$ & 0.35 & 0.09 & 0.30 & 0.07 & $0.013^{*}$ & 0.19 & 0.07 & 0.18 & 0.03 & 0.215 \\
\hline $22: 1 n-9$ & 0.05 & 0.02 & 0.03 & 0.02 & $0.004^{*}$ & $<\mathrm{LOQ}$ & & $<\mathrm{LOQ}$ & & \\
\hline $24: 1 n-9$ & $2 \cdot 17$ & 0.39 & 1.89 & 0.30 & $0.002^{*}$ & 0.95 & 0.24 & 1.00 & 0.23 & 0.348 \\
\hline Total monoenes & $17 \cdot 27$ & 1.63 & $16 \cdot 77$ & 1.24 & 0.108 & $14 \cdot 70$ & $2 \cdot 33$ & $15 \cdot 01$ & 1.80 & 0.500 \\
\hline \multicolumn{11}{|l|}{$n-6$} \\
\hline $20: 4 n-6$ & 13.63 & $1 \cdot 15$ & 14.04 & $1 \cdot 20$ & $0 \cdot 151$ & $10 \cdot 27$ & 1.58 & $10 \cdot 41$ & 1.68 & 0.705 \\
\hline $22: 5 n-6$ & 0.56 & 0.13 & 0.62 & 0.14 & 0.080 & 0.28 & $0 \cdot 11$ & 0.31 & 0.11 & 0.149 \\
\hline Total $n-6$ & $30 \cdot 85$ & 1.57 & 31.63 & 1.79 & $0.027^{*}$ & $36 \cdot 31$ & $2 \cdot 19$ & 35.49 & $2 \cdot 40$ & 0.142 \\
\hline \multicolumn{11}{|l|}{$n-3$} \\
\hline $20: 5 n-3$ & 0.51 & 0.22 & 0.54 & 0.22 & 0.566 & 0.58 & 0.28 & 0.60 & 0.26 & 0.639 \\
\hline $22: 6 n-3$ & $3 \cdot 36$ & 1.07 & 3.36 & 0.95 & 0.987 & 2.56 & 0.80 & 2.57 & 0.80 & 0.961 \\
\hline Total $n-3$ & 6.06 & 1.41 & $6 \cdot 10$ & 1.30 & 0.885 & 4.31 & 1.03 & 4.41 & 1.07 & 0.663 \\
\hline $18: 1 n-9$ DMA & 0.91 & 0.35 & 0.98 & 0.49 & 0.435 & 0.29 & $0 \cdot 17$ & 0.22 & 0.06 & $0.008^{*}$ \\
\hline $18: 1 n-7$ DMA & $0 \cdot 18$ & 0.09 & 0.13 & 0.15 & $0.003^{*}$ & $<\mathrm{LOQ}$ & & $<\mathrm{LOQ}$ & & \\
\hline Total DMA & $6 \cdot 67$ & 0.52 & $6 \cdot 77$ & 0.47 & 0.332 & $2 \cdot 39$ & 0.48 & $2 \cdot 19$ & 0.33 & $0.044^{*}$ \\
\hline Total PUFA & 36.91 & $1 \cdot 78$ & 37.73 & 1.63 & $0.025^{\star}$ & $40 \cdot 62$ & $2 \cdot 20$ & 39.9 & $2 \cdot 12$ & 0.176 \\
\hline $20: 4 n-6: 20: 5 n-3$ & 32.74 & $18 \cdot 31$ & 29.68 & $9 \cdot 65$ & 0.318 & 23.93 & $16 \cdot 82$ & $20 \cdot 15$ & 7.79 & 0.191 \\
\hline
\end{tabular}

LOQ, limit of quantification; DMA, dimethyl acetals.

${ }^{*} P<0.05$.

but $22: 4 n-6,22: 5 n-6$ and total $n-6$ fatty acids were all reduced in the autism + fish oil group while $18: 3 n-3$, $20: 4 n-3$, EPA, $22: 5 n-3$, DHA and total $n-3$ fatty acids were all increased in the autism + fish oil group (Table 3 ). As in erythrocytes, the $n-6: n-3$ and ARA:EPA ratios were both decreased in the autism + fish oil group compared with the autism group.

\section{Discussion}

The results of the present study do not suggest that the autism population in general have a problem with abnormal PL metabolism although there are subtle changes in specific fatty acids and ratios that might indicate problems with some individuals in the study groups. While we initially set the level of significance at $P<0.05$ this would not take account of multiple comparisons and, thus, if a stricter level of significance set at $P<0.0025$ were applied then most of the values presented in Tables 1-3 would not be significant. Correction for multiple comparisons prevents accidental significance being assigned when combining and comparing data from unrelated sources, for example, data from different tissue or cell types. However, when considering membrane fatty acid analysis from one cell type or plasma fraction, a level of significance set at $P<0.0025$ is probably not necessary. This is supported by studies in the literature involving fatty acid datasets from similar pair-matched studies ${ }^{(22,33,34)}$.

The most notable difference between the erythrocyte fatty acids from the autism and TD study groups was an increased
ARA:EPA ratio in the former. A similar increase in this ratio was also seen in plasma PL fatty acids in the autism group compared with the TD group. This increased ratio was also seen in an earlier study where children with autism were compared with adolescent and adult controls ${ }^{(21)}$ but no difference in the ARA:EPA ratio was seen in the study by Bu et al. ${ }^{(22)}$. In the latter, the mean erythrocyte ARA:EPA ratio varied from 66 to 72 which is much higher than the values of 23 and 17 seen in the autism and TD groups in the present study. This may be due to higher $n$ - 6 PUFA intake, relative to $n-3$ PUFA, in the US diet or perhaps differences in methodology used in the two studies. By comparison, the ARA:EPA ratio in two different groups of UK adults, conducted in our own laboratories in 2006-7, was 15.8 and $16 \cdot 7^{(35)}$ (JG Bell, EE MacKinlay and JR Dick, unpublished results).

ARA and EPA are competitive substrates for the production of eicosanoids, including, inter alia, $\mathrm{PG}$, thromboxanes and leukotrienes (LT) that are involved in the generation and modulation of inflammatory responses ${ }^{(36)}$. Compared with ARA, EPA is less favoured for eicosanoid synthesis by the cyclo-oxygenase and lipoxygenase enzymes that generate PG and LT, respectively, but EPA can inhibit production of the more bioactive PG and LT at a number of steps in their synthetic pathways ${ }^{(37,38)}$. Thus, the dietary balance of $n-6$ and $n-3$ fatty acid intake can affect the concentration and bioactivity of these cellular mediators. The tissue ARA:EPA ratio is regarded as an inflammatory index since ARA produces eicosanoids that stimulate aggregation and 
Table 3. Fatty acid compositions of erythrocyte and plasma polar lipids (weight $\%$ of total fatty acids) in patients with autism who met the agreed participation criteria compared with those excluded due to consumption of fish oil supplements in the preceding 6 months $\dagger$ (Mean values and standard deviations)

\begin{tabular}{|c|c|c|c|c|c|c|c|c|c|c|}
\hline \multirow[b]{3}{*}{ Fatty acids } & \multicolumn{4}{|c|}{ Erythrocytes } & \multirow[b]{3}{*}{$P$} & \multicolumn{4}{|c|}{ Plasma } & \multirow[b]{3}{*}{$P$} \\
\hline & \multicolumn{2}{|c|}{ Autism ( $n$ 49) } & \multicolumn{2}{|c|}{$\begin{array}{l}\text { Autism + fish } \\
\text { oil }(n 21)\end{array}$} & & \multicolumn{2}{|c|}{ Autism (n 49) } & \multicolumn{2}{|c|}{$\begin{array}{l}\text { Autism }+ \text { fish } \\
\text { oil }(n 21)\end{array}$} & \\
\hline & Mean & SD & Mean & SD & & Mean & SD & Mean & SD & \\
\hline \multirow{2}{*}{\multicolumn{11}{|c|}{ Monoenes }} \\
\hline & & & & & & & & & & \\
\hline $18: 1 n-9$ & $12 \cdot 97$ & 1.36 & $12 \cdot 72$ & 1.05 & 0.417 & 11.53 & $2 \cdot 15$ & $10 \cdot 52$ & 1.64 & $0.036^{*}$ \\
\hline $18: 1 n-7$ & 1.27 & 0.18 & 1.47 & 0.28 & $0.005^{\star}$ & 1.38 & 0.22 & 1.52 & 0.27 & $0.045^{\star}$ \\
\hline $20: 1 n-9$ & 0.34 & 0.08 & 0.33 & 0.09 & 0.437 & 0.20 & 0.07 & 0.28 & 0.08 & $0.0002^{*}$ \\
\hline $24: 1 n-9$ & $2 \cdot 15$ & 0.39 & 1.99 & 0.39 & 0.139 & 0.97 & 0.26 & 0.99 & 0.31 & 0.776 \\
\hline Total monoenes & $17 \cdot 28$ & 1.53 & 17.02 & 1.09 & 0.435 & 14.89 & $2 \cdot 25$ & $14 \cdot 10$ & 1.66 & 0.112 \\
\hline \multicolumn{11}{|l|}{$n-6$} \\
\hline $20: 4 n-6$ & $13 \cdot 62$ & $1 \cdot 17$ & $12 \cdot 29$ & 1.38 & $0.0005^{\star}$ & $10 \cdot 19$ & 1.64 & 9.83 & 1.69 & 0.413 \\
\hline $22: 4 n-6$ & $2 \cdot 61$ & 0.40 & 2.02 & 0.38 & $<0.0001^{*}$ & 0.48 & $0 \cdot 10$ & 0.38 & 0.11 & $0.0007^{*}$ \\
\hline $22: 5 n-6$ & 0.56 & 0.13 & 0.38 & $0 \cdot 12$ & $<0.0001^{\star}$ & 0.27 & $0 \cdot 10$ & $0 \cdot 18$ & 0.08 & $0.0002^{*}$ \\
\hline Total $n-6$ & $30 \cdot 73$ & 1.61 & $28 \cdot 36$ & $2 \cdot 29$ & $0.0002^{*}$ & 36.05 & $2 \cdot 50$ & 34.53 & $2 \cdot 78$ & $0.037^{\star}$ \\
\hline \multicolumn{11}{|l|}{$n-3$} \\
\hline $18: 3 n-3$ & 0.15 & 0.05 & 0.18 & 0.06 & 0.130 & 0.19 & $0 \cdot 10$ & 0.28 & 0.09 & $0.001^{*}$ \\
\hline $20: 4 n-3$ & 0.05 & 0.04 & 0.06 & 0.04 & 0.372 & 0.09 & 0.07 & 0.14 & 0.08 & $0.025^{\star}$ \\
\hline $20: 5 n-3$ & 0.53 & 0.23 & 1.09 & 0.61 & $0.0005^{\star}$ & 0.61 & 0.29 & 1.40 & 1.00 & $0.002^{*}$ \\
\hline $22: 5 n-3$ & 2.01 & 0.42 & $2 \cdot 29$ & 0.46 & $0.022^{*}$ & 0.94 & 0.22 & $1 \cdot 16$ & 0.33 & $0.008^{\star}$ \\
\hline $22: 6 n-3$ & 3.34 & 1.01 & 4.54 & 1.24 & $0.0005^{\star}$ & 2.57 & 0.75 & 3.93 & 1.27 & $0.0001^{*}$ \\
\hline Total $n-3$ & 6.08 & $1 \cdot 30$ & $8 \cdot 15$ & 1.74 & $<0.0001^{*}$ & 4.40 & 1.02 & $6 \cdot 91$ & 2.03 & $<0.0001^{*}$ \\
\hline Total PUFA & $36 \cdot 81$ & 1.70 & 36.51 & 2.02 & 0.548 & $40 \cdot 46$ & 1.34 & 41.43 & $2 \cdot 21$ & 0.071 \\
\hline$n-6: n-3$ & $5 \cdot 33$ & $1 \cdot 37$ & 3.70 & $1 \cdot 18$ & $<0.0001^{*}$ & $8 \cdot 70$ & $2 \cdot 45$ & 5.47 & 1.85 & $<0.0001^{*}$ \\
\hline $20: 4 n-6: 20: 5 n-3$ & $31 \cdot 15$ & $16 \cdot 60$ & 14.46 & 7.97 & $<0.0001^{\star}$ & $22 \cdot 21$ & $15 \cdot 25$ & $9 \cdot 18$ & 4.82 & $<0.0001^{*}$ \\
\hline
\end{tabular}

${ }^{*} P<0.05$.

†Two-sample $t$ test comparing autism $(n 49)$ with autism patients who were taking fish oil supplements $(n 21)$.

inflammatory responses via 2-series PG and 4-series LT while the 3-series PG/5-series LT, derived from EPA, have opposing activities $^{(39)}$.

Comparing the erythrocyte PL fatty acids in autism and DD groups, the latter had reduced concentrations of $20: 0,22: 0$, $24: 0,20: 1 n-9,22: 1 n-9,24: 1 n-9$ and $18: 1 n-7$ DMA and increased concentrations of total $n-6$ fatty acids and total PUFA, compared with the autism group. The long-chain fatty acids 24:0 and 24:1n-9 are important components of myelinated nerve axons and synapses in brain white matter where they can comprise up to 48 and $16 \%$ of fatty acids in glyco- and sphingolipids, respectively ${ }^{(40)}$. Thus, these changes may reflect suboptimal myelin development amongst the DD children. The reductions in $20: 0,22: 0,20: 1 n-9$ and $22: 1 n-9$ might indicate that these fatty acids are being utilised to synthesise $24: 0$ and $24: 1 n-9$ in the DD group. The study by $\mathrm{Bu}$ et al. ${ }^{(22)}$ observed an increase in $20: 1 n-9$ and $22: 1 n-9$ in patients with regressive autism compared with TD controls. These MUFA are minor components of membrane lipids but are found at higher levels in neutral lipids where they are substrates for energy production by $\beta$-oxidation. It was suggested ${ }^{(22)}$ that this elevation of MUFA might reflect an impairment in this energy production pathway as seen in patients with mitochondrial dysfunction which has been recorded in psychiatric disorders, including autism $^{(41,42)}$. However, a similar elevation was not observed in the present study.

The final part of the present study compared treatment-naive autism patients with autism patients who had taken fish oil supplements over the previous 6 months. Of the $n-6$ fatty acids, ARA, 22:4n-6, 22:5n-6 and total n-6 PUFA were reduced in fish oil-supplemented patients compared with the unsupplemented group. The reduction in ARA and its elongation-desaturation products in the fish oil-supplemented group is due to competition between EPA and ARA for the $s n-2$ position on PL, displacement of ARA by EPA and reduced synthesis of C22 HUFA. This is seen in most studies with EPA-rich supplements ${ }^{(43,44)}$. In the erythrocyte $n-3$ fatty acids, fish oil intake increased EPA, $22: 5 n-3$, DHA and total $n-3$ fatty acids and reduced $n-6: n-3$ and ARA:EPA ratios. As with the reductions in $n-6$ HUFA, these changes in $n-3$ fatty acids are similar to those recorded in other studies using fish oil supplementation ${ }^{(43,44,45)}$.

The changes in plasma fatty acids in autism patients who took fish oil were similar to those in erythrocytes, except that ARA was not reduced. In ADHD patients given fish oil, plasma ARA remained unchanged or increased following supplementation $^{(45,46)}$. Of the $n-3$ fatty acids, the same fatty acids were increased and decreased as in erythrocytes but $18: 3 n-3,20: 4 n-3$ and total PUFA were also increased, reflecting the abundance of these fatty acids in fish oil. These changes are consistent with other studies where patients have taken fish oil supplements including schizophrenia, ADHD, cystic fibrosis and autism ${ }^{(21,43,45,47)}$.

The relatively minor changes observed in erythrocytes and plasma fatty acids in children with autism compared with TD children does not support a general 'phospholipid spectrum disorder' in the autism population. Similarly, there is no evidence, based on the results of the present study, for providing all autism patients with fish oil supplements. 
However, a number of noteworthy points arose from the present study. First, there was a relative reduction in $n-3$ fatty acids and/or a relative increase in $n-6$ fatty acids in the autism population compared with TD children, as evidenced by the increased ARA:EPA ratio in the former. The ranges for this ratio in the autism and TD groups, 11.2-100.2 and $11 \cdot 8-46 \cdot 8$, respectively, suggests there are children in the autism group with very high ratios that may indicate problems in addition to poor dietary intake. We were not able to obtain a prospective dietary history from the children in the study because ethically we had to obtain an opportunistic blood sample from the children in the control group. If we had chosen to gather this information from the children in the autism group in advance of the blood sampling, then we may have introduced confounders by drawing the families' attention to the HUFA content of their child's diet. However, recent work by Herndon et al. ${ }^{(48)}$ suggests that children with autism differ from controls in their lower intake of dairy products and $\mathrm{Ca}$ and so it would appear that whilst we cannot discount a possible contribution of diet, this is unlikely to fully explain the differences seen. It was also apparent that the $n-3$ HUFA in all the groups studied were significantly lower than values reported in UK adults ${ }^{(21,35)}$. There is also evidence that $n$-3 HUFA are significantly higher in neonates and infants ${ }^{(49,50)}$ compared with the children in the present study. However, we do not know whether levels in children would be expected to be lower than those in infancy and adult life but the fact that they rose to similar levels following supplementation suggests that the levels are suboptimal. In addition, autism patients given fish oil had erythrocyte DHA levels which were similar to both UK adult and neonate values. Therefore, when we compare these findings with animal studies, and $n-3$ HUFA in neural development in young humans ${ }^{(8,9,39)}$, the low levels seen in Scottish children in the present study are concerning. Whilst the evidence for efficacy of HUFA supplementation in conditions such as autism and ADHD still needs to be fully delineated ${ }^{(51)}$, we have demonstrated that it is effective at a biochemical level in promoting what is generally considered to be a more optimal ratio ${ }^{(34,45,46,52,53)}$. Future studies should consider these areas as well as using molecular techniques to establish whether specific problems with HUFA retention and metabolism exist in a cohort of children with autism.

\section{Acknowledgements}

The present study was supported by funding from the Chief Scientist Office of the Scottish government (project CZB-4-256).

Thanks are also due to Dr Livar Frøyland and Dr Pedro Araujo of the Norwegian Institute for Nutrition and Seafood Research for their advice on statistical analysis.

J. G. B. was the principal investigator and wrote the manuscript with contributions from all other authors. D. M. was the research nurse responsible for patient recruitment, collection and processing of blood samples and administration of clinical aspects of the study. D. J. M. and R. M. B. were responsible for analysis of phospholipase. E. E. M. and J. R. D. were responsible for all aspects of fatty acid analyses. S. C. was responsible for recruitment and assessment of all DD patients. A. E. O. was the joint principal investigator responsible for all clinical aspects of the study. C. G. was responsible for most of the statistical analyses of data derived from the project. All authors read and approved the findings of the study.

None of the authors had a conflict of interest.

\section{References}

1. Baird G, Simonoff E, Pickles A, et al. (2006) Prevalence of disorders of the autism spectrum in a population cohort of children in South Thames: the Special Needs and Autism Project (SNAP). Lancet 368, 210-215.

2. Harrison MJ, O'Hare AE, Campbell H, et al. (2006) Prevalence of autistic spectrum disorders in Lothian, Scotland an estimate using the 'capture-recapture' technique. Arch Dis Child 91, 16-19.

3. Baron-Cohen S, Scott FJ, Alison C, et al. (2009) Prevalence of autism-spectrum conditions: UK school-based population study. Br J Psych 194, 500-509.

4. Blaxhill MF, Baskin DS \& Spitzer WO (2003) The changing prevalence of autism in California. J Autism Dev Disorders 33, 223-226.

5. Richardson AJ \& Ross MA (2000) Fatty acid metabolism in neurodevelopmental disorder: a new perspective on associations between attention-deficit/hyperactivity disorder, dyslexia, dyspraxia and the autistic spectrum. Prostaglandins Leukot Essent Fatty Acids 63, 1-9.

6. Young $\mathrm{G} \&$ \& Conquer $\mathrm{J}$ (2005) Omega-3 fatty acids and neuropsychiatric disorders. Reprod Nutr Dev 45, 1-28.

7. Horrobin DF \& Bennett CN (2003) Phospholipid metabolism and the pathophysiology of psychiatric and neurodevelopmental disorders. In Phospholipid Spectrum Disorders in Psychiatry and Neurology, pp. 3-47 [M Peet, IAM Glen and DF Horrobin, editors]. Carnforth: Marius Press.

8. Uauy R \& Dangour AD (2006) Nutrition in brain development and aging: role of essential fatty acids. Nutr Rev 64, S24-S33.

9. Ruxton CHS, Calder PC, Reed SC, et al. (2005) The impact of long-chain $n$-3 polyunsaturated fatty acids on human health. Nutr Res Rev 18, 113-129.

10. Sprecher H (1999) An update on the pathways of polyunsaturated fatty acid metabolism. Curr Opin Clin Nutr Metab Care 2, 135-138.

11. Pawolsky RJ, Hibbeln JR, Novotny JA, et al. (2001) Physiological compartmental analysis of $\alpha$-linolenic acid metabolism in adult humans. J Lipid Res 42, 1257-1265.

12. Burdge GC, Jones AE \& Wootton SA (2002) Eicosapentaenoic and docosapentaenoic acids are the principal products of $\alpha$-linolenic acid metabolism in young men. Br J Nutr $\mathbf{8 8}$, $355-363$.

13. Burdge GC \& Wootton SA (2002) Conversion of $\alpha$-linolenic acid to eicosapentaenoic, docosapentaenoic and docosahexaenoic acids in young women. Br J Nutr 88, 411-420.

14. Constantino JN \& Todd RD (2003) Autistic traits in the general population: a twin study. Arch Gen Psychiatry 60, 524-530.

15. Kim HY (2007) Novel metabolism of docosahexaenoic acid in neural cells. J Biol Chem 282, 18661-18665.

16. Orr SK \& Bazinet RP (2008) The emerging role of docosahexaenoic acid in neuroinflammation. Curr Opinion Invest Drugs 9, 735-743.

17. Bazan NG (2005) Lipid signalling in neural plasticity, brain repair, and neuroprotection. Mol Neurobiol 32, 89-103.

18. Brookes KJ, Chen W, Xu X, et al. (2006) Association of fatty acid desaturase genes with attention-deficit/hyperactivity disorder. Biol Psychiatry 60, 1053-1061.

19. Scaeffer L, Gohlke H, Muller M, et al. (2006) Common genetic variants of the FADS1 FADS 2 gene cluster and their reconstructed haplotypes are associated with the fatty acid 
composition in phospholipids. Human Mol Genetics 15, $1745-1756$

20. Vancassel S, Durand G, Barthelemy C, et al. (2001) Plasma fatty acid levels in autistic children. Prostaglandins Leukot Essent Fatty Acids 65, 1-7.

21. Bell JG, MacKinlay EE, Dick JR, et al. (2004) Essential fatty acids and phospholipase $\mathrm{A}_{2}$ in autistic spectrum disorders. Prostaglandins Leukot Essent Fatty Acids 71, 201-204.

22. $\mathrm{Bu} \mathrm{B}$, Ashwood P, Harvey D, et al. (2006) Fatty acid compositions of red blood cell phospholipids in children with autism. Prostaglandins Leukot Essent Fatty Acids 74, 215-221.

23. Lord C, Rutter M \& Le Couteur A (1994) Autism Diagnostic Interview - Revised: a revised version of a diagnostic interview for care givers of individuals with possible pervasive developmental disorders. J Autism Dev Disord 24, 659-685.

24. Scottish Intercollegiate Guidelines Network (2007) Guideline 98: Assessment, diagnosis and clinical interventions for children and young people with autism spectrum disorders: a national clinical guideline. http://www.sign.ac.uk/guidelines/fulltext/98/ index.html (accessed 30 April 2009).

25. World Health Organization (1993) The ICD-10 Classification of Mental and Behavioural Disorders - Diagnostic Criteria for Research. Geneva, Switzerland: WHO.

26. American Psychiatric Association (1994) Diagnostic and Statistical Manual for Mental Disorders (DSM-IV), 4th ed. Washington, DC: APA.

27. Harrison MJ, O'Hare AE, Campbell H, et al. (2006) Prevalence of autistic spectrum disorders in Lothian, Scotland and estimated using the capture-recapture technique. Arch Dis Child 91, 16-19.

28. Goodman R, Ford T \& Simmons H (2000) Using the Strengths and Difficulties Questionnaire (SDQ) to screen for child psychiatric disorders in a community sample. $\mathrm{Br} J$ Psychiatry 177, 534-539.

29. Sparrow SS \& Cicchetti DV (1985) Diagnostic uses of the Vineland Adaptive Behaviour Scales. J Pediatr Psychol 10 215-225.

30. Bligh EG \& Dyer WJ (1959) A rapid method of total lipid extraction and purification. Can J Biochem Physiol 37, 911-917.

31. Folch J, Lees M \& Sloane Stanley GH (1957) A simple method for the isolation and purification of total lipides from animal tissues. J Biol Chem 226, 497-509.

32. Christie WW (2003) Preparation of derivatives of fatty acids In Lipid Analysis, 3rd ed., pp. 205-224 [PJ Barnes, editor]. Bridgwater, UK: The Oily Press.

33. Aupperle RL, Denney DR, Lynch SG, et al. (2008) Omega-3 fatty acids and multiple sclerosis: relationship to depression. J Behav Med 31, 127-135.

34. Clayton EH, Hanstock TL, Hirneth SJ, et al. (2008) Long-chain omega-3 polyunsaturated fatty acids in the blood of children and adolescents with juvenile bipolar disorder. Lipids $\mathbf{4 3}$, $1031-1038$

35. Cyhlarova E, Bell JG, Dick JR, et al. (2007) Membrane fatty acids, reading and spelling in dyslexic and non-dyslexic adults. Eur Neuropsychopharmacol 17, 116-121.

36. Calder PC (2003) n-3 Polyunsaturated fatty acids and inflammation: from molecular biology to the clinic. Lipids 38, $342-352$.

37. Galli C, Marangoni F \& Petroni A (1992) Modulation of arachidonic acid metabolism in cultured rat astroglial cells by long-chain n-3 fatty acids. Adv Exp Med Biol 318, 115-120.
38. Jump DB (2002) The biochemistry of $n-3$ polyunsaturated fatty acids. J Biol Chem 277, 8755-8758.

39. Allessandri J-M, Guesnet P, Vancassel S, et al. (2004) Polyunsaturated fatty acids in the central nervous system: evolution of concepts and nutritional implications throughout life. Reprod Nutr Dev 44, 509-548.

40. Ledeen RW, Yu RK \& Eng LF (1973) Gangliosides of human myelin: sialosyl galactosylceramide (G7) as a major component. J Neurochem 21, 829-839.

41. Clark-Taylor T \& Clark-Taylor BE (2004) Is autism a disorder of fatty acid metabolism? Possible dysfunction of mitochondrial $\beta$-oxidation by long chain acyl-CoA dehydrogenase. Med Hypotheses 62, 970-975.

42. Shao L, Martin MV, Watson SJ, et al. (2008) Mitochondrial involvement in psychiatric disorders. Ann Med $\mathbf{4 0}$, 281-295.

43. Stevens L, Zhang W, Peck L, et al. (2003) EFA supplementation in children with inattention, hyperactivity and other disruptive behaviours. Lipids 38, 1007-1021.

44. Panchaud A, Sauty A, Kernan Y, et al. (2006) Biological effects of a dietary omega-3 polyunsaturated fatty acids supplementation in cystic fibrosis patients: a randomized, crossover placebo-controlled trial. Clin Nutr 25, 418-427.

45. Katan MB, Deslypere JP, van Birgelen AP, et al. (1997) Kinetics of the incorporation of dietary fatty acids into serum cholesteryl esters, erythrocyte membranes, and adipose tissue: an 18 month controlled study. J Lipid Res 38, 2012-2022.

46. Stevens LJ, Zental SS, Deck JL, et al. (1995) Essential fatty acid metabolism in boys with attention-deficit hyperactivity disorder. Am J Clin Nutr 62, 761-768.

47. Puri B \& Richardson AJ (2003) Long-term follow up of a single patient with schizophrenia treated with ethyl-EPA alone. In Phospholipid Spectrum Disorders in Psychiatry and Neurology, pp. 377-390 [M Peet, IAM Glen and DF Horrobin, editors]. Carnforth, UK: Marius Press.

48. Herndon AC, Di Guiseppi C, Johnson SL, et al. (2009) Does nutritional intake differ between children with autism spectrum disorders and children with typical development? J Autism Dev Disord 39, 212-222.

49. Pontes PV, Torres AG, Trugo NMF, et al. (2006) n-6 and n-3 Long-chain polyunsaturated fatty acids in the erythrocyte membrane of Brazilian preterm and term neonates and their mothers at delivery. Prostaglandins Leukot Essent Fatty Acids 74, 117-123.

50. Smithers LG, Gibson RA, McPhee A, et al. (2008) Effect of two doses of docosahexaenoic acid (DHA) in the diet of preterm infants on infant fatty acid status: results from the DINO trial. Prostaglandins Leukot Essent Fatty Acids 79, 141-146.

51. Bent S, Bertoglio K \& Hendren RL (2009) Omega-3 fatty acids for autistic spectrum disorder: a systematic review. J Autism Dev Disord 39, 1145-1154.

52. Moriguchi T, Greiner RS \& Salem N Jr (2000) Behavioural deficits associated with dietary induction of decreased brain docosahexaenoic acid concentration. $J$ Neurochem $\mathbf{7 5}$, $2563-2573$.

53. Richardson AJ \& Puri BK (2002) A randomized double-blind, placebo-controlled study of the effects of supplementation with highly unsaturated fatty acids on ADHD-related symptoms in children with specific learning difficulties. Prog Neuropsychopharmacol Biol Psychiatry 26, 233-239. 